\title{
Oxidative stress and antibacterial properties of a graphene oxide-cystamine nanohybrid
}

\author{
This article was published in the following Dove Press journal: \\ International Journal of Nanomedicine \\ 12 January 2015 \\ Number of times this article has been viewed
}

\author{
Sitansu Sekhar Nanda' \\ Seong Soo A An' \\ Dong Kee $\mathrm{Yi}^{2,3}$ \\ 'Department of Bionanotechnology, \\ Gachon University, Seongnam, South \\ Korea; ${ }^{2}$ Department of Chemistry, \\ ${ }^{3}$ Department of Environmental \\ Engineering, Myongji University, \\ Yongin, South Korea
}

\begin{abstract}
Oxidative stress can damage proteins, DNA, and lipids, and is involved in the progression of many diseases. Damage to infected cells caused by oxidative stress is related to increased levels of reactive oxygen species, including hydrogen peroxide. During oxidative stress, hydrogen peroxide levels are often increased and catalase level decreased inside cells. This can lead to the death of skin and other cells. Hydrophobic low molecular weight compounds are useful in treating hemorrhagic conditions of the skin. To this end, cystamine has been successfully conjugated with graphene oxide (GO) as a drug carrier. The current study used the microdilution method to determine the minimum inhibitory concentrations of cystamine-conjugated GO against four types of pathogenic bacteria. Minimum inhibitory concentrations values were $1 \mu \mathrm{g} / \mathrm{mL}$ against Escherichia coli and Salmonella typhimurium, $6 \mu \mathrm{g} / \mathrm{mL}$ against Enterococcus faecalis, and $4 \mu \mathrm{g} / \mathrm{mL}$ against Bacillus subtilis. Toxicity of the conjugate against squamous cell carcinoma 7 cells was minimal at low concentrations, but increased in a dose-dependent manner. These results demonstrated that our protocol produced a cystamine-conjugated GO with low cytotoxicity, but strong reactive oxygen species effects and high antibacterial activity. This nanohybrid may be useful in the treatment of dermatological disorders. Moreover, this class of nanohybrid may have other biomedical applications due to their low cytotoxicity and high antibacterial activity.
\end{abstract}

Keywords: graphene, oxide, cystamine conjugate, reactive oxygen species, antibacterial, oxidative stress

\section{Introduction}

The cellular generation of reactive oxygen species (ROS) exposes aerobic living organisms to what is referred to as the "oxygen paradox"; a situation where oxygen is necessary for life but potentially hazardous because the ROS produced may cause cell and tissue injury. These effects of oxygen on living organisms are recognized by extensive free radical research. ${ }^{1-9}$

Graphene oxide (GO) has a large surface area that can be used for the immobilization of various biomolecules. GO has been proposed as a candidate for drug delivery. ${ }^{10,11}$ Although the biological applications of GO have not been well-studied, its biocompatibility was studied successfully in fibroblast cells (L-929) ${ }^{12}$ and it has been employed as a carrier for controlled drug delivery and the release of anticancer drugs. ${ }^{13,14}$ Previous studies also reported that graphene induced oxidative stress on neural pheochromocytoma-derived PC12 cells, ${ }^{15}$ and Liu et al reported PEGylated nano-GO could be used to deliver water insoluble anticancer drugs without any toxicity. ${ }^{10,11}$

After oxidation, hydroxyl and carboxyl groups are formed in $\mathrm{GO}$ and, when conjugated, such particles can be effectively dispersed in aqueous solutions. ${ }^{16}$ By conjugating GO with cystamine, we designed a material expected to induce cell death by generating 
ROS. Cystamine contains disulfide bonds (S-S) that are a primary structural component of some proteins. ${ }^{17}$ For example, disulfide bonds are found in cell-surface proteins. ${ }^{17}$ ERO1 is classified as a sulfhydryl oxidase. Experiments have shown that the ERO1 protein contains ERO1 $\alpha$ and ERO1 $\beta$ that convert oxygen to hydrogen peroxide $\left(\mathrm{H}_{2} \mathrm{O}_{2}\right) \cdot{ }^{18,19}$ In order to increase the production of ROS, we conjugated cystamine with GO, which can easily interact with sulfhydryl oxidases. ${ }^{19}$

Various studies have shown the antibacterial activity of graphene-based materials. $\mathrm{Hu}$ et al examined the activity of graphene-based antibacterial activity toward Escherichia coli DH5 $\alpha{ }^{20}$ Similarly, Akhavan and Ghaderi demonstrated the toxicity of graphene and GO nanowalls toward E. coli and Staphylococcus aureus. ${ }^{21}$ Lim et al studied the fabrication of graphene-chitosan composite films and investigated their antibacterial properties. ${ }^{22}$ Krishnamoorthy et al reported the antibacterial activity of GO-decorated textile fabrics against $E$. coli and $S$. aureus. ${ }^{23}$ Recently, graphene functionalized antimicrobial peptides have been used for the bioselective detection of bacteria at cellular levels. ${ }^{24}$ These studies motivated us to investigate the antibacterial activity of cystamine-conjugated GO.

The present research emphasized a new family of cystamine-conjugated and GO-mediated drug delivery systems. Here, we described the chemical synthesis of this nanocarrier. Fourier transform infrared spectroscopy was used to elucidate the interaction between constituents and to characterize the product of the chemical synthesis. All toxicity experiments were performed using murine squamous cell carcinoma (SCC7) cells.

\section{Materials and methods Synthesis of GO}

The synthesis of GO was carried out through a modification of Hummer's method. ${ }^{28}$ Briefly, a mixture of graphite flakes $(2 \mathrm{~g})$ and sodium nitrate $(1 \mathrm{~g})$ was cooled to $0^{\circ} \mathrm{C}$ in an ice bath. Concentrated sulfuric acid $(60 \mathrm{~mL})$ was added to the mixture and then potassium permanganate $(9 \mathrm{~g})$ was added slowly to keep the reaction temperature below $5^{\circ} \mathrm{C}$. When the addition of potassium permanganate was complete, the reaction mixture was warmed to $35^{\circ} \mathrm{C}$ and stirred for 7 hours. The reaction mixture was then cooled to room temperature and poured into ice water $(55 \mathrm{~mL})$. Then, $7 \mathrm{~mL}$ of hydrogen peroxide was added, followed by the addition of $90 \mathrm{~mL}$ of ice water after separation. The reaction was subsequently stirred for 7 hours and then subjected to filtration. After filtration, the product was washed three times with hydrochloric acid and then with deionized water for 120 hours. All chemicals were purchased from Sigma-Aldrich Co. (St Louis, MO,
USA) except hydrogen peroxide which was purchased from Daejon Chemicals.

\section{Synthesis of cystamine-conjugated GO}

Aqueous suspensions of GO (1 mg/mL in $10 \mathrm{~mL})$ were prepared by sonicating GO for 1 hour. Cystamine conjugation was performed by adding GO suspensions $(50 \mu \mathrm{g} / \mathrm{mL})$ to a buffered solution of cystamine ( $2 \mathrm{mg}$ of cystamine in $10 \mathrm{mM}$ Tris buffer, $\mathrm{pH}$ 8.5). After shaking for 2 hours, conjugated GO was collected on a cellulose membrane filter, washed three times with deionized water, and dried under vacuum.

\section{Viability of SCC7 cells treated with cystamine-conjugated GO}

Murine SCC7 cells were cultured with cystamine-conjugated GO for 24 hours at concentrations from 5-300 $\mu \mathrm{g} / \mathrm{mL}$. The MTT (3-(4,5-dimethylthiazol-2-yl)-2,5-diphenyltetrazolium bromide) assay was used to measure cell survival as a percentage of viable cells in comparison to untreated controls. After treatment with cystamine-conjugated GO, $200 \mu \mathrm{L}$ of a $0.5 \mathrm{~g} / \mathrm{L}$ MTT solution in Roswell Park Memorial Institute medium-1640 (1:10) was added to each well. Cells were incubated at $37^{\circ} \mathrm{C}$ for 2 hours to allow color to develop, and $200 \mu \mathrm{L}$ of $20 \%$ dimethyl sulfoxide was added. Absorbance was measured at $570 \mathrm{~nm}$.

\section{Production of ROS by cystamine- conjugated GO}

The oxidant-sensitive dye $2^{\prime}, 7^{\prime}$-dichlorofluorescein diacetate (DCFH-DA) was used to assess the production of ROS. SCC7 cells were plated in 96 -well plates $\left(5 \times 10^{3}\right.$ cells per well) and incubated for 24 hours. Cells were then treated with 5-200 $\mu \mathrm{g} / \mathrm{mL}$ GO or cystamine-conjugated GO and incubated for an additional 24 hours. Positive controls involved culturing cells in the presence of $200 \mathrm{mM} \mathrm{H} \mathrm{O}_{2}$ prepared 1 hour before adding to cells loaded with the DCFH-DA probe. The probe was loaded into cells by replacing the culture medium with $100 \mu \mathrm{L}$ of fresh medium containing $20 \mu \mathrm{M}$ DCFH-DA. Cells were washed with D-Hank's buffer solution after 1 hour. Then, $100 \mu \mathrm{L}$ of D-Hank's buffer solution was added to each well and fluorescence intensity measured using a microplate reader at $485 \mathrm{~nm}$.

Relative amounts of ROS were calculated as $\left(\mathrm{F}_{\text {test }}-\mathrm{F}_{\text {blank }}\right) /$ $\left(\mathrm{F}_{\text {control }}-\mathrm{F}_{\text {blank }}\right)$, where $\mathrm{F}_{\text {test }}$ is the fluorescence intensity of the SCC7 cells treated with GO or cystamine-conjugated GO, or the positive control, $\mathrm{F}_{\text {control }}$ is the fluorescence intensity of the control SCC7 cells, and $\mathrm{F}_{\text {blank }}$ is the fluorescence intensity of the wells without SCC7 cells. 


\section{Antibacterial activity of cystamine- conjugated GO}

The microdilution method was used with two Gram-negative bacterial strains (E. coli [KACC 10005] and S. typhimurium [KCCM 40253]) and two Gram-positive bacterial strains (Bacillus subtilis [KACC 14394] and Enterococcus faecalis [KACC 13807]) to determine the antibacterial activity of cystamine-conjugated GO. ${ }^{25} \mathrm{LB}$ was used as the diluent for both bacterial strains. Inoculates were prepared by suspending cells in sterile LB for 12 hours. Cystamine-conjugated GO and standards were placed in 96-well plates and $10^{7}$ colony forming unit $(\mathrm{CFU}) / \mathrm{mL}$ of cells were inoculated so that the final volume in each microwell was $0.2 \mathrm{~mL}$. The plates were incubated at $35^{\circ} \mathrm{C}$ for 24 hours and absorbance read at $590 \mathrm{~nm}$ using a microplate reader. Minimum inhibitory concentrations (MIC) values were determined both before and after incubation.

\section{Characterization}

A field emission scanning electron microscope (FE-SEM; JSM-7500F; JEOL, Tokyo, Japan), and an atomic force microscope (AFM; Nanoscope IIIa, Digital Instruments,
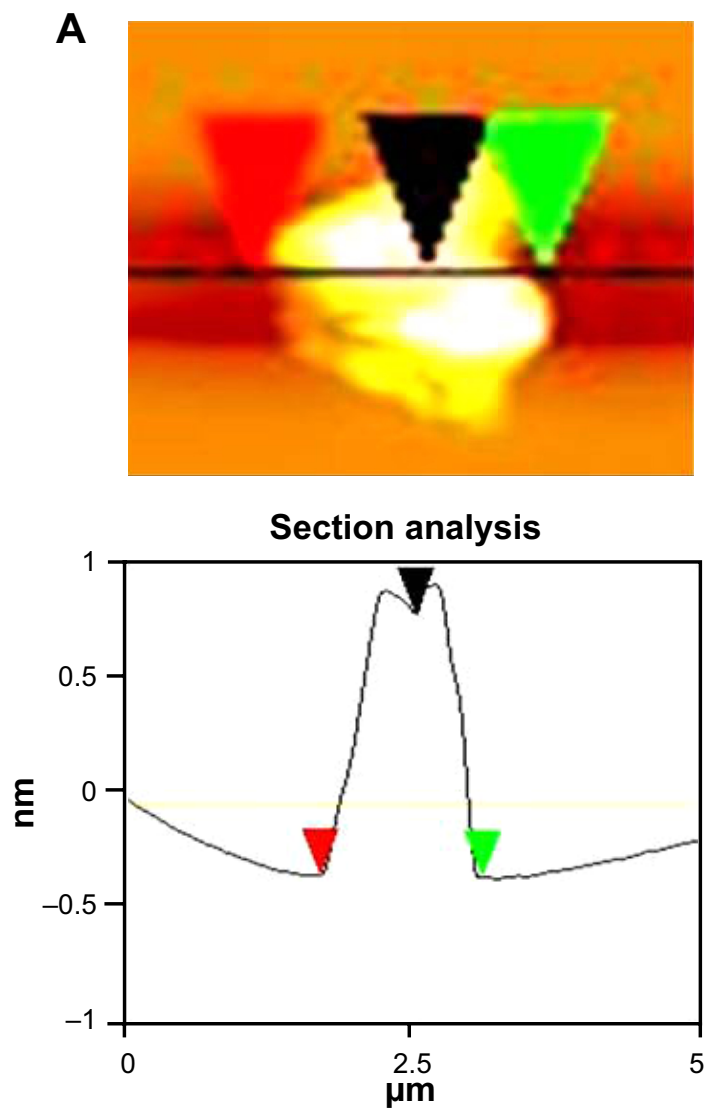

Tonawanda, NY, USA) with a J scanner were used to assess the morphology of cystamine-conjugated GO and the cells. An Escalab MK II photoelectron spectrometer (VG Scientific Ltd., East Sussex, UK) was used for X-ray photoelectron spectroscopy (XPS) measurements. A Varian ultraviolet-visible spectrophotometer was used for measuring absorbance. A Varian 3100 Fourier transform infrared (FT-IR) (Excalibur series) spectrophotometer was used for FT-IR spectra measurements. A ZetaSizer (Nano-Z; Malvern Instruments, Malvern, UK) was used for zeta potential measurement.

\section{Results and discussion}

Under acidic conditions, FT-IR did not show any carbonyl peak at $1,680 \mathrm{~cm}^{-1}$, indicating that there was no cystamine conjugated with GO. We assumed, therefore, that cystamine was oxidized under the basic $\mathrm{pH}(8.5)$ conditions used in this study resulting in redox reactions and the conjugation of cystamine to GO.

AFM (Figure 1) and SEM (Figure 2) were used to characterize the surface morphology of cystamine-conjugated GO. These data clearly showed the formation of cystamine-conjugated GO via changes in the surface morphology. In Figure 1A,

\section{B}
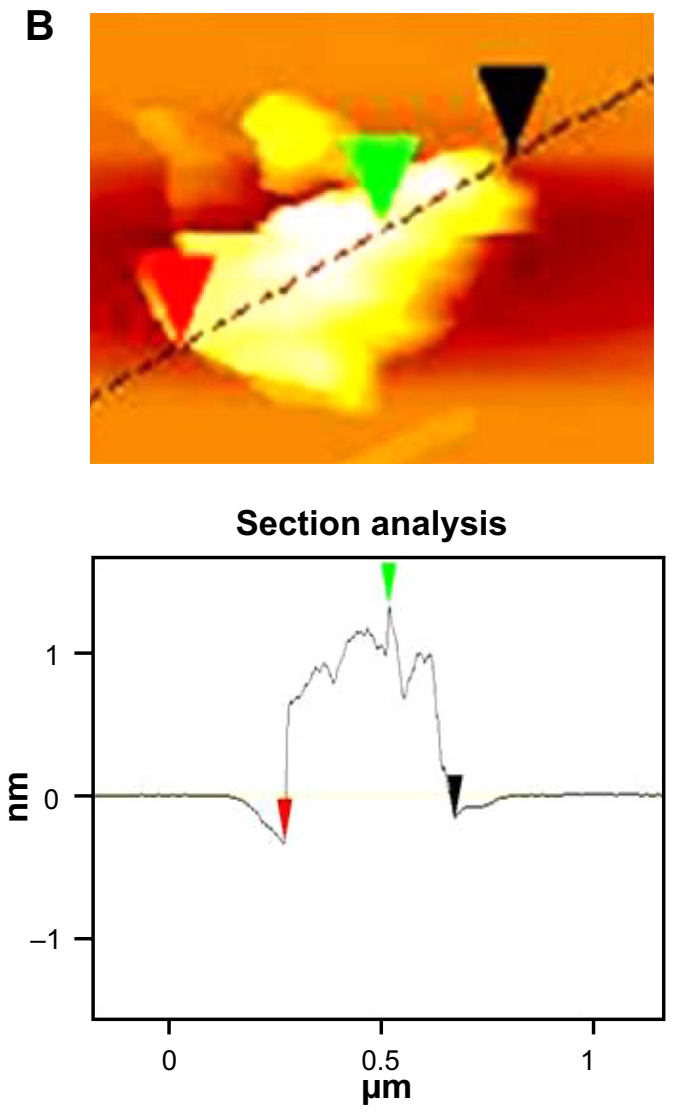

Figure I Images of graphene oxide (GO) (A) and cystamine-conjugated GO (B) by atomic force microscope (AFM). Note: Magnified AFM images of GO showed its height $0.8 \mathrm{~nm}$ whereas cystamine-conjugated GO shows its height $1.2 \mathrm{~nm}$. 

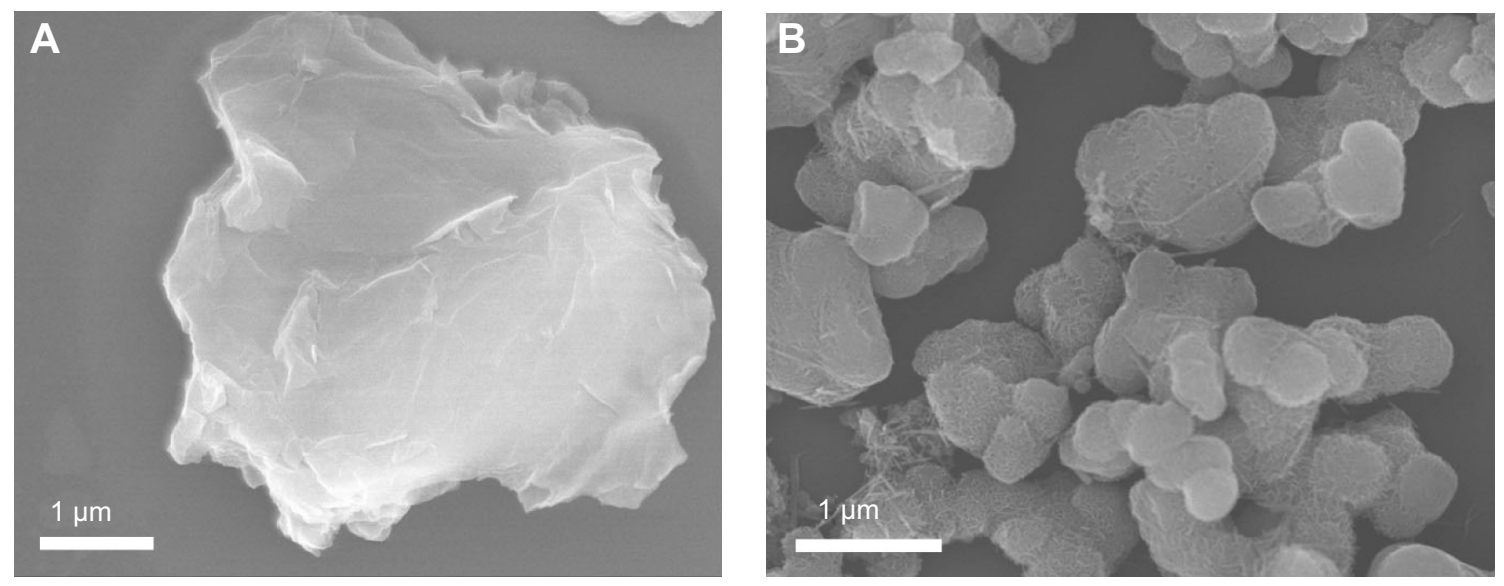

Figure 2 A typical scanning electron microscope (SEM) image of (A) dried graphene oxide (GO) and (B) dried cystamine-conjugated GO.

Note: SEM image showed conjugation of cystamine with GO which is confirmed by the reduction of the size of cystamine-conjugated GO.

the vertical distance is about $0.8 \mathrm{~nm}$, indicating the formation of single-layered GO. In Figure 1B, the vertical distance is about $1.2 \mathrm{~nm}$, indicating the conjugation of cystamine with GO. ${ }^{29}$ SEM images of GO are shown in Figure 2A while cystamine-conjugated GO are clearly visible in Figure 2B.

It is well known that unconjugated GO has bactericidal activity. In the current study, a strong biological effect against micro-organisms was always found with cystamine-conjugated GO (Figure 2B). Such nanoparticles interact with cells via disulfide bonds (S-S) and produce ROS. Therefore, we also performed a toxicity study with the SCC7 cell line. The results from the cytotoxicity tests indicated that cystamine-conjugated $\mathrm{GO}$ caused a dose-dependent decrease in cell viability (Figure 3A).

The stability of nanomaterials in a dispersed state is a major obstacle for their use in biomedicine. ${ }^{26}$ The zeta potential of cystamine-conjugated $\mathrm{GO}$, and $\mathrm{GO}$ in an aqueous dispersion, were measured and found to be -19.2 and $-49.4 \mathrm{mV}$, respectively.
GO has a negative zeta potential due to the ionization of edge carboxylic groups. Our data are thus consistent with previous studies. ${ }^{30}$ The observed zeta potential of cystamine-conjugated GO was expected because colloidal stability within -25 to +25 $\mathrm{mV}$ is indicative of its stability when dispersed. ${ }^{27}$

The absorbance spectrum of cystamine-conjugated GO in suspension showed the same peak at $232 \mathrm{~nm}$ as unconjugated GO. An additional peak at $400 \mathrm{~nm}$ showed that cystamineconjugated GO was present (Figure 4A). GO exhibits a $\pi-\pi^{*}$ transition band at $232 \mathrm{~nm}$ and a shoulder $\pi-\pi^{*}$ transition band at $400 \mathrm{~nm}$. In contrast, the $\pi-\pi^{*}$ transition peak shifts to $400 \mathrm{~nm}$ for cystamine-conjugated $\mathrm{GO}$, indicating that some groups on the GO surface are removed as the conjugated structure is created. ${ }^{29}$

Further characterization by FT-IR was performed to evaluate the conjugation of GO by cystamine. Briefly, the peaks at 3,350 and $3,180 \mathrm{~cm}^{-1}$ (amide [CO-NH] stretching) confirmed the presence of cystamine on GO (Figure 4B).
A

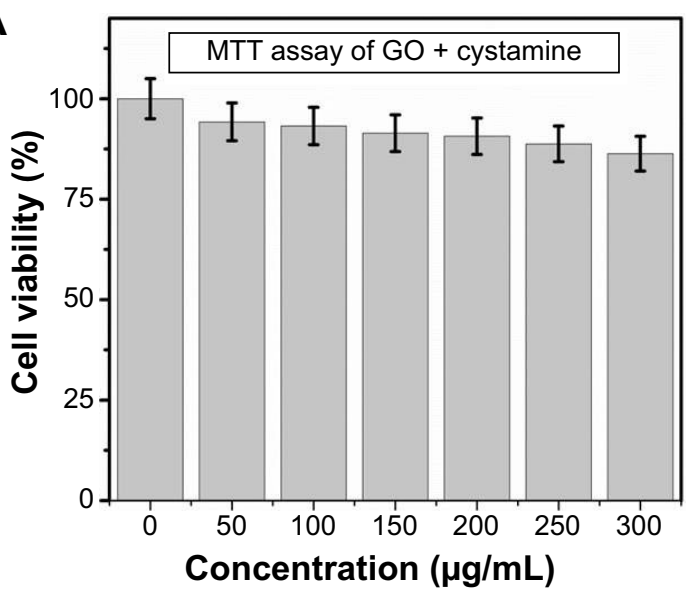

B

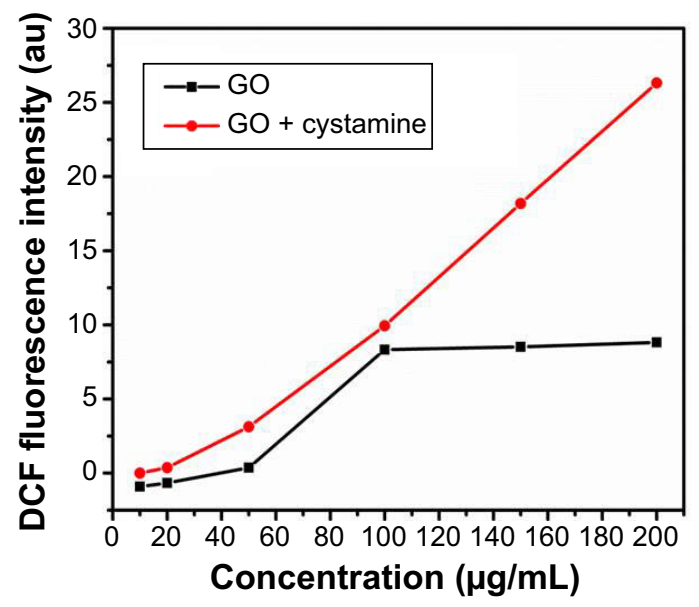

Figure 3 Cytotoxicity and ROS studies of cystamine conjugated GO

Notes: (A) Cell viability of cystamine-conjugated graphene oxide (GO). (B) Reactive oxygen species (ROS) studies of GO (black color), and cystamine-conjugated GO (red color). Abbreviations: MTT, (3-(4,5-dimethylthiazol-2-yl)-2,5-diphenyltetrazolium bromide); au, arbitrary unit; DCF, dichlorofluorescein. 

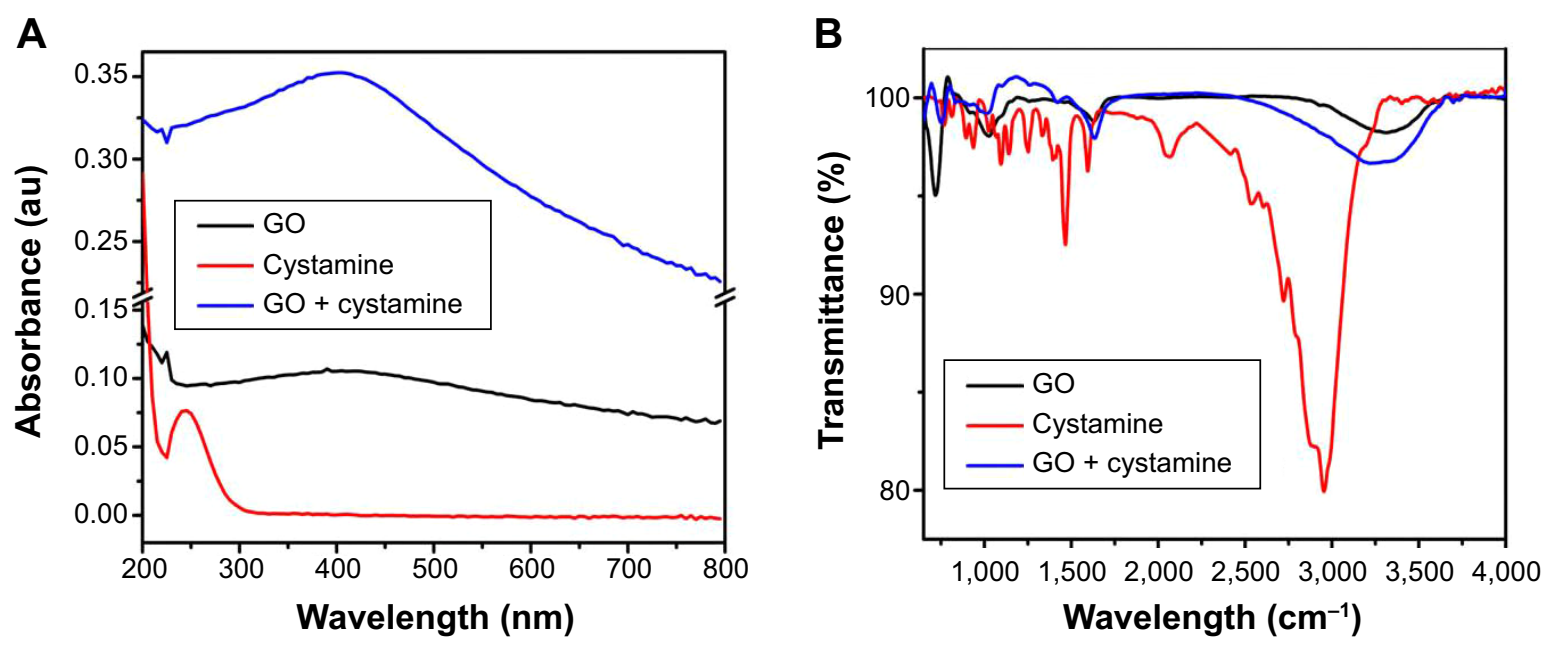

Figure 4 UV-Vis spectrum of cystamine, GO, and cystamine-conjugated GO.

Notes: (A) UV-Vis spectrum of cystamine (red color), GO (black color), and cystamine-conjugated GO (blue color). The peak of GO at $232 \mathrm{~nm}$ remains stable in cystamineconjugated GO. (B) Fourier transform infrared (FT-IR) spectroscopy of cystamine (red color), GO (black color), and cystamine-conjugated GO (blue color). FT-IR confirmed the conjugation of cystamine with GO.

Abbreviations: UV-Vis, ultraviolet-visible; GO, graphene oxide; au, arbitrary unit.

The carbonyl peak at $1,680 \mathrm{~cm}^{-1}$ was a clear indication of cystamine conjugation with GO (Figure 4B). ${ }^{29}$

XPS measurements provided additional information about the nature of cystamine-conjugated GO. Both conjugated and unconjugated $\mathrm{GO}$ exhibited $\mathrm{C}=\mathrm{C}\left(\mathrm{sp}^{2}\right), \mathrm{C}-\mathrm{C}$ $\left(\mathrm{sp}^{3}\right), \mathrm{C}=\mathrm{O}$ (carbonyl), $\mathrm{O}-\mathrm{C}=\mathrm{O}$ (carboxyl), and $\mathrm{C}-\mathrm{O} / \mathrm{C}-\mathrm{O}-\mathrm{C}$ (hydroxyl and epoxy) groups (Figure 5) ${ }^{30}$ Figure 5A shows the C1S peaks of GO including C-O (hydroxyl and epoxy, $288.1 \mathrm{eV}), \mathrm{C}=\mathrm{O}$ (carbonyl, $291.4 \mathrm{eV}), \mathrm{C}=\mathrm{C} / \mathrm{C}-\mathrm{C}(284.7 \mathrm{eV})$, and $\mathrm{O}=\mathrm{C}-\mathrm{O}$ (carboxyl, $294.8 \mathrm{eV}$ ) species. The $\mathrm{C}=\mathrm{C} / \mathrm{C}-\mathrm{C}$ peak was $45.36 \%$ of the total GO. C-O (hydroxyl and epoxy, $288.5 \mathrm{eV}$ ), $\mathrm{C}=\mathrm{O}$ (carbonyl, $291.9 \mathrm{eV}$ ), and $\mathrm{O}=\mathrm{C}-\mathrm{O}$ (carboxyl, $294.5 \mathrm{eV}$ ) peaks are shown in Figure 5B and indicate cystamine conjugation with $\mathrm{GO}$. The major species, $\mathrm{C}=\mathrm{C} / \mathrm{C}-\mathrm{C}(284.7 \mathrm{eV})$, was reduced to $36.53 \%$ of the total. Moreover, we found $0.84 \%$ of sulfur and $1.07 \%$ of nitrogen in cystamine-conjugated $\mathrm{GO}$ (Figure $\mathrm{S} 1$ ). There was $38.72 \%$ oxygen present in $\mathrm{GO}$ and $43.21 \%$ present in cystamineconjugated GO, confirming conjugation. At low concentrations, cystamine-conjugated GO produced more ROS as compared to GO, without any observed toxicity. ${ }^{31}$ There was, however, a decrease in SCC7 cell viability with cystamineconjugated GO at high concentrations. The production of ROS by cystamine-conjugated GO was low when compared to carbon nanotubes and fullerene, ${ }^{32}$ indicating that external factors were responsible for ROS production. The oxidative stress induced by cystamine-conjugated GO, but not GO, increased at higher concentrations (Figure 3B). Thus, ROS were generated in a concentration-dependent manner when cells were exposed to cystamine-conjugated GO.

In this study, antibacterial activity was determined using the microdilution method. ${ }^{25}$ The MIC of cystamine-conjugated
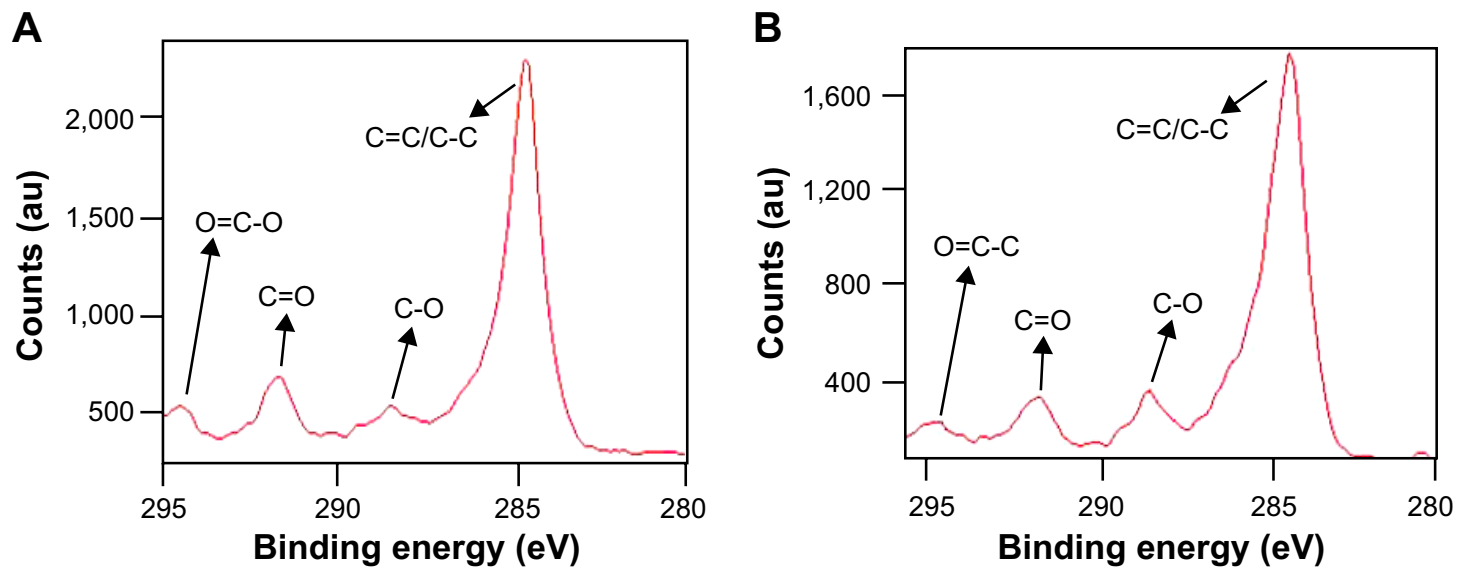

Figure 5 High resolution $\mathrm{Cl}_{\mathrm{s}}$ XPS spectra of (A) GO and (B) cystamine-conjugated $\mathrm{GO}$.

Abbreviations: GO, graphene oxide; XPS, X-ray photoelectron spectroscopy; au, arbitrary unit. 

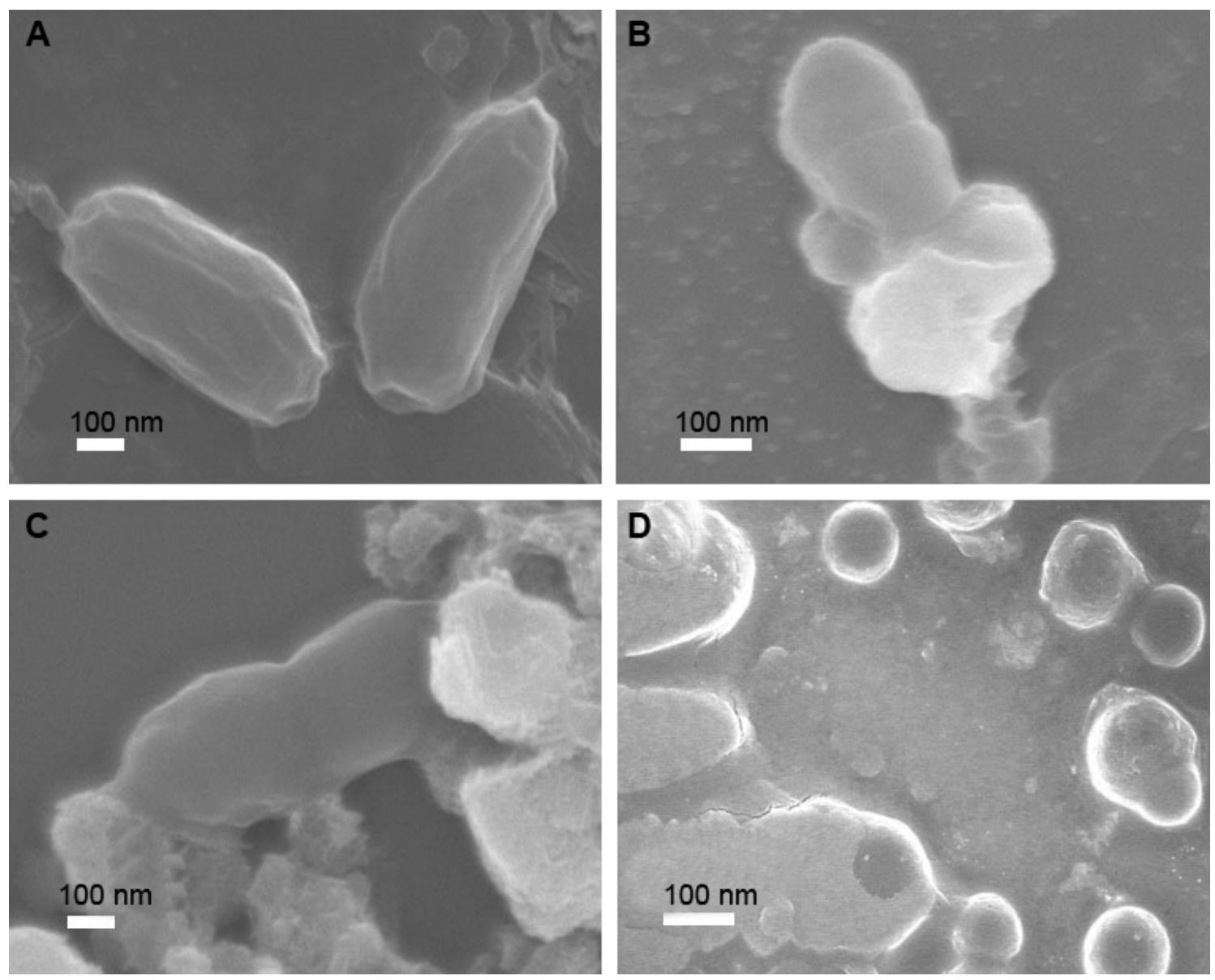

Figure 6 Scanning electron microscope (SEM) images of antibacterial activities.

Notes: SEM images of antibacterial activities of cystamine-conjugated graphene oxide (GO) against (A) Escherichia coli (B) Bacillus subtilis (C) Enterococcus faecalis (D) Salmonella typhimurium. Cystamine-conjugated GO is more toxic to Gram-negative bacteria (E. coli and S. typhimurium) as compared to Gram-positive bacteria (B. subtilis and E. faecalis).

GO were $1 \mu \mathrm{g} / \mathrm{mL}$ against $E$. coli and $S$. typhimurium, $6 \mu \mathrm{g} / \mathrm{mL}$ against $E$. faecalis, and $4 \mu \mathrm{g} / \mathrm{mL}$ against $B$. subtilis. These data showed that cystamine-conjugated GO had significant antibacterial activity. A comparative analysis was performed with a standard drug aminoglycoside antibiotic, Kanamycin (SigmaAdrich Co.). The MIC of Kanamycin were $64 \mu \mathrm{g} / \mathrm{mL}$ against E. coli and S. typhimurium, $128 \mu \mathrm{g} / \mathrm{mL}$ against $E$. faecalis and B. subtilis. Antimicrobial properties of carbon-based materials such as fullerenes, graphite oxide, carbon nanotubes, and nanocomposite forms were reported in previous studies. ${ }^{33-35}$ The general mechanism of antibacterial activity of carbon materials depends on the size, structure, and properties of the individual materials. In addition, nanoscale size distribution, high surface to volume ratio, and other physicochemical properties contribute to the antimicrobial effects.

The current results show that cystamine-conjugated GO is more toxic to Gram-negative bacteria than to Gram-positive bacteria. This result is consistent with the previous findings of $\mathrm{Hu}$ et al and Akhavan and Ghaderi. ${ }^{20,21} \mathrm{Hu}$ et al in another study, demonstrated that graphene nanosheets disrupted the cell walls of $E$. coli, either through physical disruption or oxidative stress, resulting in the loss of cellular integrity. ${ }^{20}$ In our study, the differential toxicity of cystamine-conjugated GO toward Gram-negative bacteria compared to Gram-positive bacteria may be related to differences in the natures of their cell walls. A thin peptidoglycan layer (7-8 nm thickness) is present in Gram-negative bacteria whereas a thick peptidoglycan layer (20-80 nm thickness) is present in Gram-positive bacteria. ${ }^{21,36}$ The thicker peptidoglycan layer in Gram-positive bacteria may explain why these bacteria are more resistant to the antibacterial effects of cystamine-conjugated GO (Figure 6).

\section{Conclusion}

There is extensive ongoing research designed to expand our knowledge on the roles of oxidative stress and its mediators in human diseases such as atherosclerosis, cardiovascular diseases, diabetes, cancer, and neurodegenerative disorders. In the current study, we found an increased production 
of ROS in the functionalization of cystamine-conjugated GO, and demonstrated that this material exhibits good antibacterial activity against two different Gram-positive, and two different Gram-negative bacteria. In order to elucidate the mechanism of ROS production, additional studies are needed. Nevertheless, these results suggest that cystamine-conjugated GO will have an important role in the field of biomedicine.

\section{Acknowledgment}

This work was supported by the GRRC program of Gyeonggi Province (GRRC Gachon 2013-B04, Development of Microfluidic Chip for Diagnosing Diseases).

\section{Disclosure}

The authors have no conflicts of interest to disclose.

\section{References}

1. Commoner B, Townsend J, Pake GE. Free radicals in biological materials. Nature. 1954;174(4432):689-691.

2. Harman D. Aging: a theory based on free radical and radiation chemistry. J Gerontol. 1956;11(3):298-300.

3. Slater TF. Necrogenic action of carbon tetrachloride in the rat: a speculative mechanism based on activation. Nature. 1966;209(5018): $36-40$.

4. McCord JM, Fridovich I. Superoxide dismutase. An enzymic function for erythrocuprein (hemocuprein). J Biol Chem. 1969;244(22): 6049-6055.

5. Slater TF. Free Radical Mechanisms in Tissue Injury. London, UK: Pion Ltd; 1972.

6. Harman D. The aging process. Proc Natl Acad Sci U S A. 1981;78(11): 7124-7128.

7. Cadenas E. Biochemistry of oxygen toxicity. Ann Rev Biochem. 1989; 58:79-110

8. Cadenas E, Davies KJ. Mitochondrial free radical generation, oxidative stress, and aging. Free Radic Biol Med. 2000;29(3-4):222-230.

9. West JD, Marnett LJ. Endogenous reactive intermediates as modulators of cell signaling and cell death. Chem Res Toxicol. 2006;19(2): 173-194.

10. Liu Z, Robinson JT, Sun X, Dai H. PEGylated nanographene oxide for delivery of water-insoluble cancer drugs. J Am Chem Soc. 2008;130(33): 10876-10877.

11. Sun X, Liu Z, Welsher K, et al. Nano-Graphene Oxide for Cellular Imaging and Drug Delivery. Nano Res. 2008;1(3):203-212.

12. Schipper ML, Ratchford NN, Davis CR, et al. A pilot toxicology study of single-walled carbon nanotubes in a small sample of mice. Nat Nanotechnol. 2008;3(4):216-221.

13. Zhang L, Xia J, Zhao Q, Liu L, Zhang Z. Functional graphene oxide as a nanocarrier for controlled loading and targeted delivery of mixed anticancer drugs. Small. 2009;6(4):537-544.

14. Yang X, Zhang X, Liu Z, Ma Y, Huang Y, Chen, Y. High-Efficiency Loading and Controlled Release of Doxorubicin Hydrochloride on Graphene Oxide. J Phys Chem C. 2008;112:17554-17558.

15. Zhang YB, Ali SF, Dervishi E, et al. Cytotoxicity effects of graphene and single-wall carbon nanotubes in neural phaeochromocytoma-derived PC12 cells. ACS Nano. 2010;4(6):3181-3186.
16. Becerril HA, Mao J, Liu Z, Stoltenberg RM, Bao Z, Chen Y. Evaluation of solution-processed reduced graphene oxide films as transparent conductors. ACS Nano. 2008;2(3):463-470.

17. Gross E, Sevier CS, Heldman N, et al. Generating disulfides enzymatically: reaction products and electron acceptors of the endoplasmic reticulum thiol oxidase Ero1p. Proc Natl Acad Sci U S A. 2006;103(2): 299-304.

18. Baker KM, Chakravarthi S, Langton KP, Sheppard AM, Lu H, Bulleid NJ. Low reduction potential of Erolalpha regulatory disulphides ensures tight control of substrate oxidation. EMBO J. 2008;27(22): 2988-2997.

19. Wang L, Zhu L, Wang CC. The endoplasmic reticulum sulfhydryl oxidase Erolbeta drives efficient oxidative protein folding with loose regulation. Biochem J. 2011;434(1):113-121.

20. Hu W, Peng C, Luo W, et al. Graphene-based antibacterial paper. ACS Nano. 2010;4(7):4317-4323.

21. Akhavan O, Ghaderi E. Toxicity of graphene and graphene oxide nanowalls against bacteria. ACS Nano. 2010;4(10):5731-5736.

22. Lim HN, Huang NM, Loo CH. Facile preparation of graphene-based chitosan films: Enhanced thermal, mechanical and antibacterial properties. J Non-Cryst Solids. 2012;358:525-530.

23. Krishnamoorthy K, Navaneethaiyer U, Mohan R, Lee J, Kim S. Antibacterial Efficiency of Graphene Nanosheets against Pathogenic Bacteria via Lipid Peroxidation. J Appl Nanosci. 2012;2:119-126.

24. Mannoor MS, Tao H, Clayton JD, et al. Graphene-based wireless bacteria detection on tooth enamel. Nat Commun. 2012;3:763.

25. Amsterdam D. In: Lorian V, editor. Susceptibility Testing of Antimicrobials in Liquid Media. Baltimore, MD: Lippincott Williams \& Wilkins; 1996;52:111.

26. Fang C, Bhattarai N, Sun C, Zhang M. Functionalized nanoparticles with long-term stability in biological media. Small. 2009;5(14): 1637-1641.

27. Lotya M, Hernandez Y, King PJ, et al. Liquid phase production of graphene by exfoliation of graphite in surfactant/water solutions. $J \mathrm{Am}$ Chem Soc. 2009;131(10):3611-3620.

28. Hummers WS, Offeman RE. Preparation of graphitic oxide. J Am Chem Soc. 1958;80:1339-1339.

29. Yang S, Xiaosheng T, Erwin P, Junmin X. Graphene oxide based fluorescent nanocomposites for cellular imaging. Journal of material chemistry B. 2013;1:512.

30. Shin HJ, Kim KK, Benayad A, et al. Efficient Reduction of Graphite Oxide by Sodium Borohydride and Its Effect on Electrical Conductance. Adv Funct Mater. 2009;19:1987-1992.

31. Yanli C, Sheng YT, Hui LJ, et al. In vitro toxicity evaluation of graphene oxide on A549 cells. Toxicol Lett. 2011;200(3):201-210.

32. Lewinski N, Colvin V, Drezek R. Cytotoxicity of nanoparticles. Small. 2008;4(1):26-49.

33. Zhang Y, Ali SF, Dervishi E, et al. Cytotoxicity effects of graphene and single-wall carbon nanotubes in neural phaeochromocytoma-derived PC12 cells. ACS Nano. 2010;4(6):3181-3186.

34. Garza KM, Soto KF, Murr LE. Cytotoxicity and reactive oxygen species generation from aggregated carbon and carbonaceous nanoparticulate materials. Int J Nanomed. 2008;3(1):83-94.

35. Niu A, Han Y, Wu J, Yu N, Xu Q. Synthesis of One-Dimensional Carbon Nanomaterials Wrapped by Silver Nanoparticles and Their Antibacterial Behavior. J Phys Chem C. 2010;114:12728-12735.

36. Eaton P, Fernandes JC, Pereira E, Pintado ME, Malcata FX. Atomic force microscopy study of the antibacterial effects of chitosans on Escherichia coli and Staphylococcus aureus. Ultramicroscopy. 2008; 108(10):1128-1134. 


\section{Supplementary material}
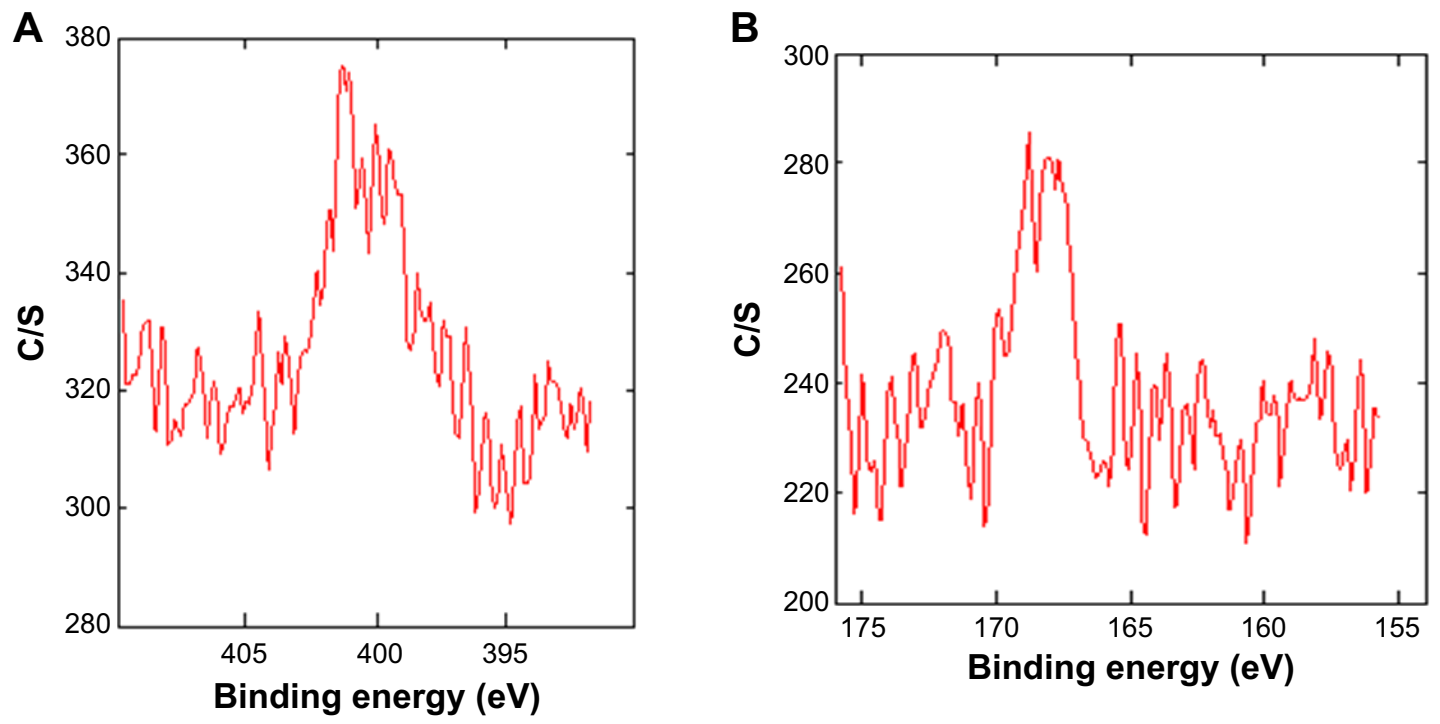

Figure SI High resolution (A) $\mathrm{NI}_{\mathrm{S}}$ XPS spectra (B) $\mathrm{SI}_{\mathrm{S}}$ XPS spectra.

Abbreviations: XPS, X-ray photoelectron spectroscopy; $\mathrm{c} / \mathrm{s}$, counts per second.

\section{Publish your work in this journal}

The International Journal of Nanomedicine is an international, peerreviewed journal focusing on the application of nanotechnology in diagnostics, therapeutics, and drug delivery systems throughout the biomedical field. This journal is indexed on PubMed Central, MedLine, CAS, SciSearch $\AA$, Current Contents $\AA /$ Clinical Medicine,

Journal Citation Reports/Science Edition, EMBase, Scopus and the Elsevier Bibliographic databases. The manuscript management system is completely online and includes a very quick and fair peer-review system, which is all easy to use. Visit http://www.dovepress.com/ testimonials.php to read real quotes from published authors. 